Given the extent of medical and mental health needs, often unmet, in children attending for CPMEs, Children's Services might consider seeking medical reviews at an earlier stage for children known to them.

If educational and mental health professionals, and where relevant, Looked After Children's teams, had closer links to these medical assessments, then the CPME could prove a powerful tool in addressing the multiple needs of these vulnerable children.

\section{G500(P) PRE-CERVICAL MYOSITIS OSSIFICANS SECONDARY TO NON-ACCIDENTAL TRAUMA}

C Parfitt, N Sargant. General Paediatrics, Bristol Children's Hospital, Bristol, UK

\subsection{6/archdischild-2020-rcpch.425}

We present a case report of a 7 week old baby, presenting with pre-cervical myositis ossificans secondary to non-accidental trauma.

Myositis Ossificans is characterised by bone formation within muscle or soft tissue. Majority of cases are caused by trauma. These usually occur in the extremities in older men and rarely in the head and neck area.

The baby presented to the Ear, Nose and Throat (ENT) team with a sub-lingual mass and stridor. Chest X-ray revealed multiple rib fractures of varying ages. An MRI scan of the neck detected a C6 vertebral body fracture and a pre-cervical calcified mass. A biopsy confirmed the diagnosis of myositis ossificans.

Skeletal survey also detected fractures involving the clavicle, humerus, bilateral tibiae and 5 th metatarsal. Review by a Specialist in paediatric endocrinology and metabolic bone disease found no clinical, radiological or biochemical evidence of metabolic bone disease.

On clinical review, the baby was noted to have a linear submental laceration, mucosal tear of the soft palate and bruising of the tongue. No explanation was provided to account for these findings. History of an apparent life threatening event where mouth to mouth resuscitation was required with a delay in presentation to healthcare raised further concern about possible non-accidental injury.

Lower cervical spine injuries in infants are incredibly rare and accidental injuries tend to cause fractures in the upper cervical vertebrae. We have found one case report describing a C5 fracture with pre-cervical myositis ossificans in an infant seconadry to non accidental injury. The case histories and images are strikingly similar.

This case report highlights an atypical presentation of myositis ossificans in both age and location. It is important to raise awareness of this rare finding so that it can be considered in other cases and lead to earlier identification. These cases may trigger a case series to raise awareness of pre-cervical myositis ossificans as a marker for non-accidental injury.

\section{G501(P) CULTURALLY BASED PRACTICES IN CHILD PROTECTION: A FRAMEWORK}

${ }^{1} E$ Botcher, ${ }^{2}$ G Gifford. 'General Paediatrics, University Hospitals of Coventry and Warwickshire NHS Trust, Coventry, UK; ${ }^{2}$ Community Paediatrics, Coventry and Warwickshire Partnership NHS Trust, Coventry, UK

10.1136/archdischild-2020-rcpch.426
We live in a multicultural society and as paediatricians it is important for us to consider our patients within the context of their own culture. Culture is defined as societal norms and behaviours that change with geography, time, or even within generations of a family. What may be acceptable to one society may be utterly unacceptable in another.

Child Protection centres on the law of the land in which a potential crime has been committed in. Safeguarding however is not only about whether something is legal or illegal, it focuses on whether there is significant harm or risk of harm.

Cultural practices which may be harmful can be grouped into four overlapping areas: Gender Based Practices, Medicinal Practices, Body Modification for Cultural Identity, and Punishment. An event may fall into two or more categories, and they also fall along a spectrum of acceptability. For example, the piercing of a baby girl's ears would be a gender-based practice that has elements of bodily modification for cultural identity, but rarely would this be a safeguarding issue. If the baby girl in question had been subject to Female Genital Mutilation however, this would be a clear safeguarding (and legal) issue.

Following a local case which provoked discussion with the safeguarding team, the following framework was developed to consider whether something is a safeguarding issue:

- Is it legal in the UK?

- Is it harmful? (Including the degree of risk of harm)

- Is it morally/culturally acceptable?

In cases where a child presents to paediatricians for a child protection medical and there is doubt about whether an event or procedure is a safeguarding issue, this framework adds clarity and helps to structure conversations within the multidisciplinary team.

\section{G502(P) THE CHILD PROTECTION RECOGNITION AND RESPONSE (CPRR) COURSE, THE NEPALESE EXPERIENCE, 2016- 2019}

${ }^{1} \mathrm{D}$ Upadhyay, ${ }^{2} \mathrm{R}$ Chapagain, ${ }^{3} \mathrm{~N}$ Sabde, ${ }^{4} \mathrm{C}$ Hobbs, ${ }^{5} \mathrm{~J}$ Acharya, ${ }^{6} \mathrm{~S}$ Sharma, ${ }^{7} \mathrm{~J}$ Lott, ${ }^{8} \mathrm{~B}$ Giri, ${ }^{9} \mathrm{D}$ Jellinek, ${ }^{9} \mathrm{~J}$ Price, ${ }^{10} \mathrm{~S}$ Shrestha, ${ }^{8} \mathrm{~J}$ Mae, ${ }^{9} \mathrm{R}$ Smith, ${ }^{11} \mathrm{R}$ Kayastha, ${ }^{11} \mathrm{~B}$ Banjhade. ${ }^{1} \mathrm{Comm}$ Paediatrics, CPFT, Cumbria, Barrow in Furness, UK; ${ }^{2}$ Hospital Paediatrics, Kanti Children Hospital, Kathmandu, Nepal; ${ }^{3}$ Comm Pediatrics(Retired), CPF, Cumbria, UK; ${ }^{4}$ Comm Paediatrics(Retired), Previously St James Hospital, Leeds, UK; ${ }^{5}$ Developmental Pediatrics, Alder Hey CH Hospital, Liverpool, UK; ${ }^{6}$ General Paediatrics, Sheer Memorial Hospital, Banepa, Nepal; ${ }^{7}$ Safeguarding Nurse, CMFT, Manchester Children Hospital, Manchester, UK; ${ }^{8}$ Hospital Paediatrician, Kanti Children Hospital, Kathmandu, Nepal; ${ }^{9}$ Retired Consultant Comm Pediatrician, UK; ${ }^{10}$ Hospital Paediatrician, Nepal Medical Hospital, Kathmandu, Nepal; ${ }^{11}$ Sister, Kanti Children Hospital, Kathmandu, Nepal

\subsection{6/archdischild-2020-rcpch.427}

Background The RCPCH CPRR course was developed following the Lord Laming Inquiry (2003) after the death of Victoria Climbie in 2000. These Courses are run by ALSG (Advanced life supportgroup) in several centres and adopted abroad in some countries including Nepal.

Aims

- To raise awareness of child abuse and neglect in Nepal.

- To encourage effective response including referrals to the appropriate agency.

- To support the development of a multi-agency response in the Nepalese context.

Methods and Results In 2016, the first Nepalese course was conducted at Kanti Children Hospital, Kathmandu by the 